\title{
Simulating Fertilization of the Ocean as a Carbon Sequestration Strategy: Effectiveness and Unintended Consequences
}

\author{
K. Caldeira
}

March 20, 2002

U.S. Department of Energy

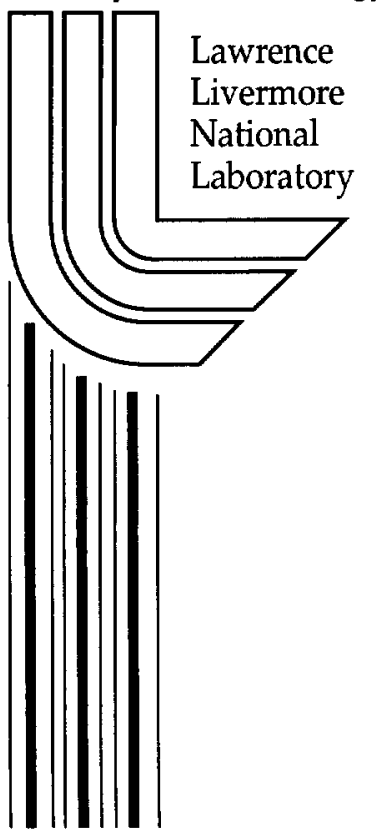




\section{DISCLAIMER}

This document was prepared as an account of work sponsored by an agency of the United States Government. Neither the United States Government nor the University of California nor any of their employees, makes any warranty, express or implied, or assumes any legal liability or responsibility for the accuracy, completeness, or usefulness of any information, apparatus, product, or process disclosed, or represents that its use would not infringe privately owned rights. Reference herein to any specific commercial product, process, or service by trade name, trademark, manufacturer, or otherwise, does not necessarily constitute or imply its endorsement, recommendation, or favoring by the United States Government or the University of California. The views and opinions of authors expressed herein do not necessarily state or reflect those of the United States Government or the University of California, and shall not be used for advertising or product endorsement purposes.

This work was performed under the auspices of the U. S. Department of Energy by the University of California, Lawrence Livermore National Laboratory under Contract No. W-7405-Eng-48.

This report has been reproduced directly from the best available copy.

Available electronically at http://www.doc.gov/bridge

Available for a processing fee to U.S. Department of Energy

And its contractors in paper from

U.S. Department of Energy

Office of Scientific and Technical Information

P.O. Box 62

Oak Ridge, TN 37831-0062

Telephone: (865) 576-8401

Facsimile: (865) 576-5728

E-mail: reports@adonis.osti.gov

Available for the sale to the public from

U.S. Department of Commerce

National Technical Information Service

5285 Port Royal Road

Springfield, VA 22161

Telephone: (800) 553-6847

Facsimile: (703) 605-6900

E-mail: orders@ntis.fedworld.gov

Online ordering: $\underline{\text { http://www.ntis.gov/ordering.htm }}$

OR

Lawrence Livermore National Laboratory

Technical Information Department's Digital Library

http://www.llnl.gov/tid/Library.html 


\section{Simulating Fertilization of the Ocean as a Carbon Sequestration Strategy: Effectiveness and Unintended Consequences Abstract}

Provide an abstract of no more than 250 words. Give the broad, long-term objectives and what the specific research proposed is intended to accomplish. State the hypotheses to be tested. Indicate how the proposed research addresses the SC scientific/technical area specifically described in this announcement.

The primary objectives of this project are to assess, and improve our understanding of:

1. The effectiveness of various strategies to intentionally store carbon in the ocean through fertilization of the surface ocean with iron and/or macronutrients;

1. Unanticipated environmental consequences of these ocean fertilization strategies.

We propose to use what may be the best global ocean biogeochemical model in the world (PISCES) and apply it to perform the most realistic global-scale simulations of various iron fertilization scenarios. Versions of PISCES are currently used by MPI in Germany and IPSL in France. The model represents diatoms, coccolithophorids, and two classes of zooplankton. This model considers $\mathrm{Fe}, \mathrm{N}, \mathrm{P}, \mathrm{O}_{2}, \mathrm{Si}$, alkalinity, and carbon; for some of these it considers dissolved inorganic and organic, as well as particulate, forms. We would install the PISCES model with a minimum of modification into the LLNL ocean model, and perform an initial suite of simulations of both iron fertilization experiments (e.g., SOFeX) and proposed iron fertilization strategies. Based on the simulated experiments, we will analyze model deficiencies with respect to the observations and use this analysis to improve future versions of the model. The source code for and results from this set of models will be freely distributed, and thus should help groups performing related work elsewhere.

This project the most-realistic ocean fertilization simulations yet performed in a global model, with an assessment of and improvement in the reliability of those predictions using results from iron fertilization experiments such as SOFeX. These results will help provide context and guidance for biological observations within the ocean carbon sequestration research program.

267 words 


\section{Simulating Fertilization of the Ocean as a Carbon Sequestration Strategy: Effectiveness and Unintended Consequences}

\section{Background and significance}

John Martin suggested that iron availability limited phytoplankton growth in the Southern Ocean, and that this could play a role in glacial-interglacial changes in atmospheric $\mathrm{CO}_{2}(\mathrm{Martin}$ and Fitzwater, 1987). In 1988, John Gribbin proposed that fertilization of the ocean could be used "to alleviate the anthropogenic greenhouse effect" (Gribbin, 1988). John Martin began to promote the idea vigorously (Andrew J. Watson, pers. comm., 2002). Most famously, at a lecture at Woods Hole in 1993, Martin made his remark "Give me half a tanker of iron and I'll give you an Ice Age," reportedly in a mock-Strangelove voice.

Is this practical? We know that addition of Fe in some marine environments stimulates increased photosynthesis and organic carbon production. It is reasonable to assume that some of this increased organic carbon production sinks to deeper ocean layers, where it is isolated from the atmosphere for some amount of time. The increased organic carbon flux to the ocean interior would drive a partially compensating flux of carbon from the atmosphere to the near-surface ocean.

To evaluate the prospects for removing $\mathrm{CO}_{2}$ from the atmosphere by fertilizing the ocean, we need to understand both the effectiveness of this strategy and its possible unintended consequences. Especially because concerns have been raised (e.g., Chisholm and Falkowski), it is important to develop the scientific foundation needed to develop rational and informed policy.

In the next two subsections of this proposal, we discuss what needs to be known if we are to adequately appraise ocean sequestration as a fertilization strategy, first from the point of view of effectiveness and then from the point of view of unintended consequences. Following this, we review preliminary studies of ocean fertilization designed to address these uncertainties. Next, we discuss the proposed research ("Design and Methods"). Lastly, we summarize the proposed work.

\section{Effectiveness at storing carbon}

The first set of questions addresses the issue of what we need to know to determine the effectiveness of ocean fertilization as a carbon sequestration strategy.

How much, locally, will biogenic carbon export (and macronutrient export) increase for various fertilization strategies?

Most global ocean GCM simulations have represented iron fertilization by computing the organic carbon export that would be needed to draw phosphate concentrations down to zero. More sophisticated calculations have been made using regional models, but these are unable to predict long-term effectiveness. Iron fertilization experiments have 
documented increased organic carbon production, but the evidence for increased export is equivocal.

Iron fertilization may increase export locally, but does it increase global annual mean net export?

It is possible that iron fertilization causes macronutrients to be consumed more rapidly than they otherwise would have been consumed. However, if left unfertilized, those macronutrients may have been consumed somewhat later and in a different location. In other words, might a patch of fertilized ocean leave a downstream "shadow" with diminished production. Fertilization only increases total export if it increases integrated utilization of macronutrients.

Which fertilization strategies would maximize ocean $\mathrm{CO} 2$ uptake per unit iron added?

What is the optimal spatial scale and locations for iron fertilization [patchy versus widespread; in upwelling zones, zones of deep convection, in boundary currents, or gyres?]? Is it better to fertilize intermittently or continuously?

Do different fertilization strategies preferentially select for coccolithophorids, diatoms, Trichodesmium, etc., and what effect does this selection have on carbon storage?

Different classes of phytoplankton have different properties affecting ocean $\mathrm{CO} 2$ storage, such as inorganic carbon production and nitrogen fixation. Is it possible to characterize the ocean in terms of where each class is most easily stimulated and what its effect is on carbon storage.

How does macronutrient transport affect the long-term application of fertilization as a sequestration strategy?

If large tracts of the ocean were fertilized for many years, the increased export of organic matter would tend to deplete macronutrient concentrations in the upper ocean. This reduction in macronutrient content would tend to diminish biological productivity, making continued fertilization less effective. It is unknown how important this dynamic is, as a function of scale and duration of fertilization.

Will there be changes in calcareous plankton production and export that could affect air-sea carbon fluxes?

The export of the tests of calcareous plankton transports alkalinity from the surface ocean to the ocean interior or sediments. This diminishes the alkalinity of the surface ocean, which tends to drive a $\mathrm{CO} 2$ flux into the atmosphere. Iron fertilization will affect the production and export of $\mathrm{CaCO} 3$. It is important to understand the role of this production in affecting ocean carbon storage.

Where does exported carbon, and nutrients, remineralize in the water column?

Many questions about the effectiveness of ocean carbon sequestration depend on the depth to which the exported carbon (and associated nutrients) is transported. For example, carbon transported to the $3 \mathrm{~km}$ depth in the North Pacific may remain in the ocean for a thousand years, whereas carbon in the upper thermocline might be ventilated to the atmosphere with a few years. 
[It has been pointed out that even if the carbon is exported to the ocean bottom, there is some effective short-term return of some of this carbon, because the increased carbon export generates an increased mixed-layer to upper thermocline carbon gradient, resulting in an increased flux of carbon from the upper thermocline to the mixed-layer.]

Is remineralization "Redfield"?

Furthermore, the ideal situation for sequestration effectiveness would be would be one in which organic carbon is transported more deeply than nutrients. This would allow the nutrients to cycle back up to the surface more rapidly than the organic carbon, diminishing the loss of effectiveness associated with transporting macronutrients away from the euphotic zone.

Can added iron recycle and thereby repeatedly fertilize the surface ocean?

If added iron were to support export production, remineralize, and then be transported back up to the surface ocean, then this added iron could act to repeatedly fertilize the ocean. Is this a plausible hypothesis? What would the magnitude of this effect be?

\section{Unintended consequences}

The second set of questions addresses the issue of what we need to know to predict the unintended consequences of iron fertilization. Models can only represent processes that we understand to some extent, therefore the models could miss some, but not all, unanticipated consequences. An important issue is the reversibility of changes produced by ocean fertilization. If the effects of fertilization are reversible, as we presume they would be, then any closely monitored fertilization effort could be suspended at the first sign of unanticipated adverse consequences, with little long-term harm.

What are the long-term pH consequences of extensive long-term ocean fertilization?

If the ocean were fertilized for an extended amount of time over a broad area, significant amounts of carbon may be transferred from the upper ocean to the ocean interior. This would tend to diminish $\mathrm{pH}$ impacts of $\mathrm{CO} 2$ release on organisms that dwell in the upper ocean [e.g., calcareous plankton, coral reefs] while exacerbating $\mathrm{pH}$ effects on organisms that live in the mid-depth waters. What is the magnitude of the $\mathrm{pH}$ impacts of widespread, long-term, ocean fertilization?

What will happen to the ocean oxygen concentrations?

Early studies have indicated that long-term widespread ocean fertilization could produce or expand anoxic regions in the ocean. Would the avoidance of new oxygen-depleted zones significantly impact the amount of carbon that could be sequestered by ocean fertilization? What are the oxygen consequences of intermittent or patchy fertilization?

Will other radiatively active gases be affected by iron fertilization?

Phytoplankton produce DMS, nitrous oxides, and other radiatively active gases. If ocean fertilization were to produce ocean ecosystems that produce more DMS in remote marine environments, this could make ocean sequestration more effective at combating global warming; on the other hand, nitrous oxides are powerful greenhouse gases, and if these ecosystems were to produce greater amounts of nitrous oxides, this could diminish 
the effectiveness of ocean fertilization. Initial calculations suggest that these are second order effects; nevertheless, they need to be carefully and quantitatively assessed.

Is there any danger of producing irreversible changes to ocean ecosystems?

If an area of the ocean is fertilized for a prolonged period of time and then the fertilization is halted, will the ecosystem return to the status quo ante, and, if so, how long will it take to return? This question is important to answer because if a fertilization project were to start, and then a problem was discovered, it would be important to know whether the system could return to its unperturbed state. Such would not be the case, for example, if ocean fertilization were to have the capacity to drive species to extinction. Initial results indicate that ocean ecosystems are fairly resilient and could recover on a time scale that is similar to the duration of the fertilization.

Would fertilization favor some biogeochemical groups over others?

Would fertilization tend to favor coccolithophorids or diatoms? Would nitrogen-fixing organisms become more widespread? What might the unintended consequences for ecosystem structure of various fertilization strategies?

What is the impact of ocean fertilization on fisheries?

Would fertilization for carbon sequestration diminish fishery yields [because more nutrients and organic matter are being export to the ocean interior] or increase fishery yields [because of enhanced photosynthesis]? Are there trade-offs between fishery considerations and sequestration considerations, or are the goals of increasing fish yields and decreasing greenhouse gas concentrations well aligned?

\section{Preliminary studies}

Ocean fertilization was first proposed by Gribbin, and later promoted by Martin. There have been a variety of laboratory and field experiments relating to iron limitation of phytoplankton growth (). Here, we focus on a review of efforts to simulate iron fertilization.

The first set of fertilization simulations were performed in the early 1990s, and the field has had only limited progress since that time.

The biggest contributions on in recent ocean fertilization simulation research have probably come from Jorge Sarmiento's group in Princeton, Richard Matear's effort at CSIRO in Australia, and the Dick Barber/Fei Chai/etal consortium.

Caldeira et al.

Under the auspices of the DOE Center for Research on Ocean Carbon Sequestration (DOCS), we have initiated some preliminary modeling of ocean fertilization. Our

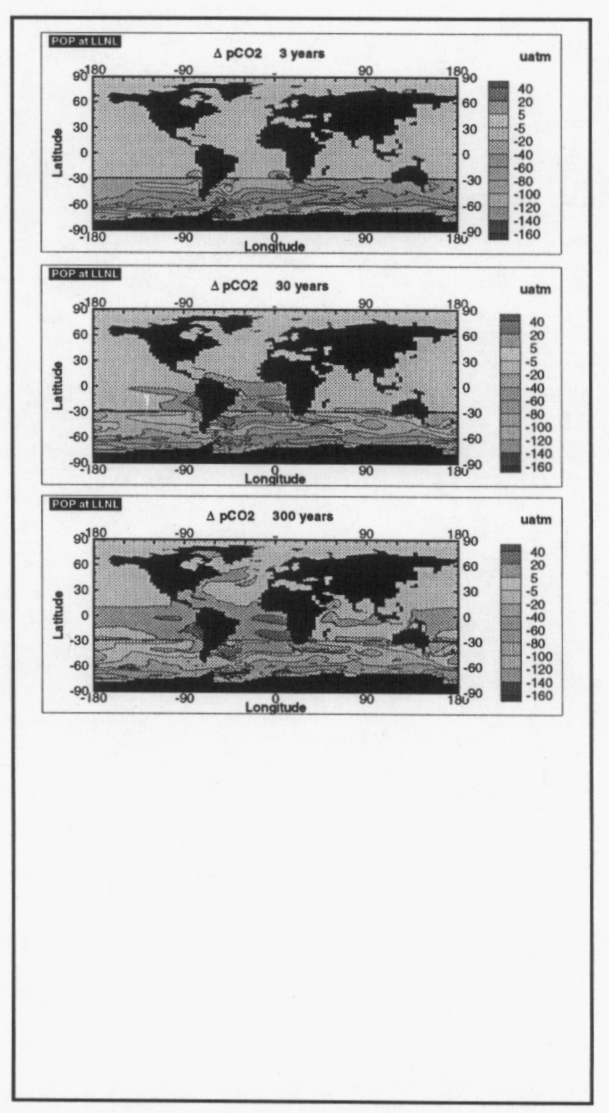


approach followed that of Orr and Sarmiento (1991) in which nutrient export is diagnosed from the mismatch between observed and predicted phosphate concentrations, with biogenic export from the euphotic zone assumed to occur in "Redfield" ratios.

\section{Orr et al, Sarmiento and Orr}

These early simulations used a "phosphate restoring" model of export production. In such a model, carbon and nutrient export is proportional to the difference between modeled and observed surface nutrient concentrations. Such an approach crudely approximates biogenic nutrient transport, but errors in ocean transport will propagate into errors in predicted export.

Sarmiento and Orr and Orr and Sarmiento simulated continuous long-term Fe fertilization over broad areas and by assuming that macronutrients were nearly completely utilized in the upper ocean.

\section{Gnanediskan and Sarmiento (in prep)}

Gnandesikan and Sarmiento have extended the work of Orr and Sarmiento by using a similar approach to look at the efficacy of patchy and/or intermittent fertilization. They have also been looking at the effect of varying remineralization length scales.

\section{Matear}

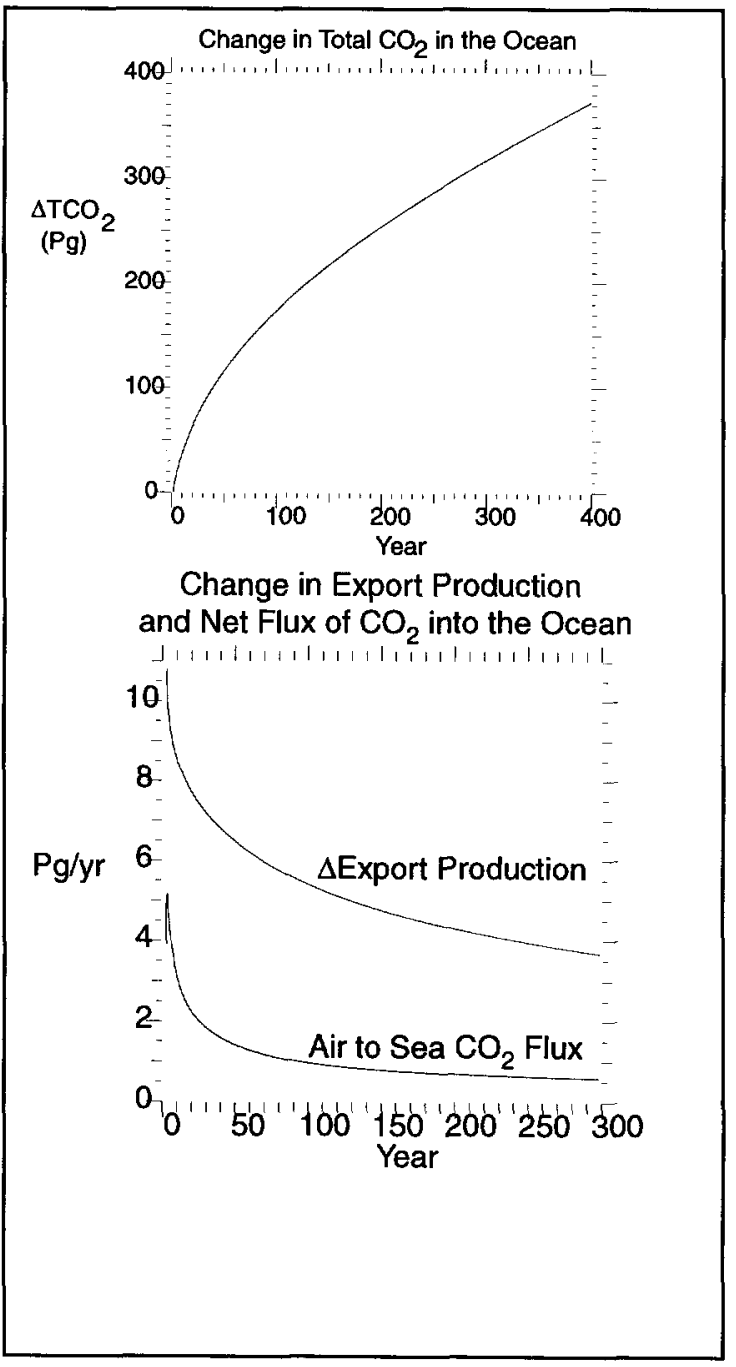

Richard Matear has used a similar approach to looking at the effect of adding iron and macronutrients

\section{Dick Barber/Fei Chai/et al}

Dick Barber/Fei Chai/et al are attempting to produce a more mechanistically realistic model of iron fertilization, which they are applying in a limited domain model. Right now, in their model, iron is not explicitly modeled, but the effects of iron are represented as a specified increase in photosynthetic rate. This approach promises to produce a quantitatively predictive mechanistic model of carbon and nutrient export from the euphotic zone. Because of its limited domain, this model cannot now predict long-term effectiveness of iron fertilization as a sequestration strategy. 


\section{Research design and methods}

\section{Model and data sharing}

We intend to work both in collaboration and competition with other ongoing efforts. We intend to make the source code for our model freely available for download on the web, for others to use, improve, criticize, etc. Numerical forms of model input files and results used in published papers will also be made available over the web.

I believe that we will all benefit when all modelers are as open as possible with their model source code and results. The reproducibility of model experiments depends on being able to examine [and execute!] the underlying code.

\section{Overall approach}

We intend to take the PISCES biogeochemical model used by MPI in Hamburg, Germany, and IPSL, in Saclay, France, and run it in the LLNL Ocean GCM. We then plan to do a series of model simulations designed to address many of the questions outlined in the first section of this document.

\section{Specific tasks}

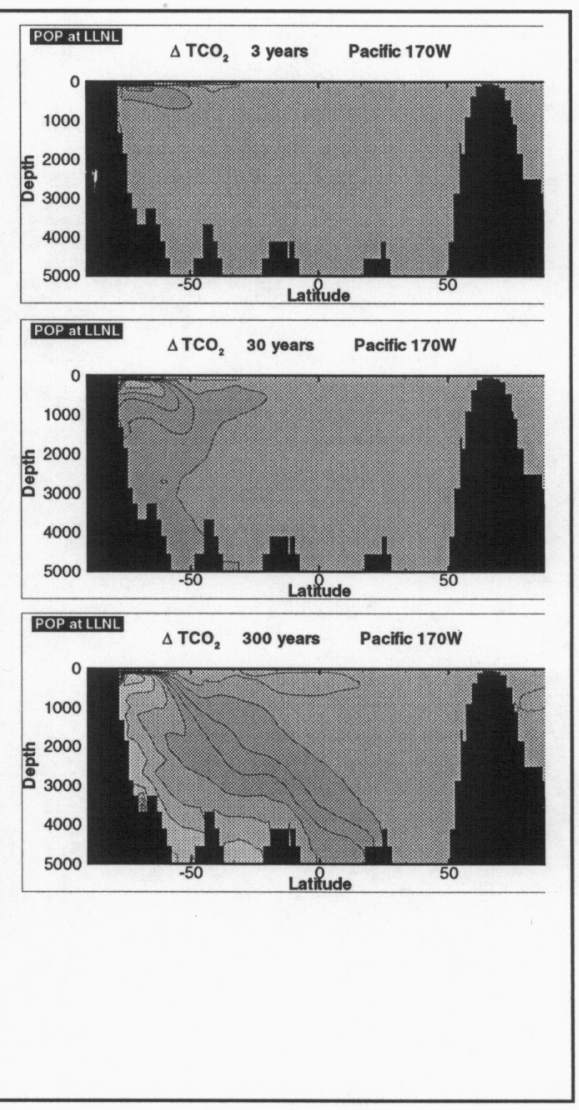

In summary, we proposed to

- Install a "cleaned up" version of the ocean biogeochemical model used by MPI and IPSL into the LLNL ocean GCM

- Spin the model up to a stationary "pre-industrial" state, and perform several standard IPCC atmospheric CO2 scenario calculations to act as a baseline for sequestration scenarios

- Perform, analyze, and publish a set of evaluation simulations [e.g., compare model results with Fe fertilization experiments (SOFeX, etc.)]

- Perform, analyze, and publish a range of simulations of various ocean fertilization strategies

○ Variations in spatial domain [e.g., small patches, large areas, different oceanic regions, etc.]

- Variations in temporal domain [e.g., continuous iron addition vs. pulsed, iron addition keyed to ecosystem state, one-time vs. repeating]

- Perform, analyze, and publish a range of simulations of various "what-if" scenarios

- What if remineralization length scales could be controlled?

- What if "Redfield" ratios of exported carbon could be controlled?

○ How would it affect long-term sequestration efficiency nutrients (e.g., P, N, Fe) were to remineralize more rapidly than carbon?

- What if we could fertilize in such a way that only some functional groups would receive the benefit of the added $\mathrm{Fe}$ (e.g., only diatoms or only coccolithophorids).

In somewhat greater detail 
Install a "cleaned up" version of the ocean biogeochemical model used by MPI and IPSL into the LLNL ocean GCM

PISCES was written by scientists, not computer specialists. As such, PISCES contains examples of what my computer colleagues consider "bad programming practice." The biogeochemical model needs to be represented as a set of differential equations, separate from the time-stepping algorithm of the model. It is hoped that this "cleaned-up" version of PISCES might be adopted by MPI and or IPSL.

The "cleaned up" version of PISCES should install into the LLNL model relatively easily. We then need to bring this model to a statistically stationary state. This involves simulating thousands of years of ocean circulation. We would then have a single model that is capable of simulating atmospheric release, direct injection, and iron fertilization.

Spin the model up to a stationary "pre-industrial" state, and perform several standard IPCC atmospheric CO2 scenario calculations to act as a baseline for sequestration scenarios

After the model is installed in our ocean GCM, it needs to be run for several thousand simulated years to produce a simulation pre-industrial state. Then, we will simulate the historical period (1765 to 2000) and several IPCC scenarios for the next century. These will act as points of comparison for various fertilization simulations.

Perform, analyze, and publish a set of evaluation simulations [e.g., compare model results with Fe fertilization experiments (SOFeX, etc.)]

There is a real mismatch in scale between the fertilization experiments, which typically occur on the scale of 10's of km, and global ocean biogeochemical models, which typically have grid cells of 100's of km. Nevertheless, it is useful to ask the question how the model results for the various Fe fertilization experiments compare with observations. Because of the larger spatial scale, the model should dilute the patch more slowly than in the real world. Nevertheless, we can ask the question of whether the dynamics that were observed bear an understandable relation to the dynamics occurring in the model.

\section{Perform, analyze, and publish a range of simulations of various ocean fertilization strategies}

We propose to perform a base set of simulations that will be used to address many different scientific questions (i.e., test many different hypotheses). These questions are described in more detail below.

\section{Variations in spatial domain}

The effect of fertilizing a small patch may differ significantly from that of fertilizing a large area. Fertilization might be more effective in some regions [e.g., Southern Ocean] than in other regions [e.g., equatorial upwelling regions]. These hypotheses will be tested in the model.

Variations in temporal domain

The effects of continuous iron addition may differ significantly from that of pulsed addition. Furthermore, it is possible that iron addition may be most effective when the iron addition is 
keyed to specific ecosystem states. For example, it might be best to fertilize when a natural bloom has already begun, or it might be best to fertilize later in the season to spur a new bloom. There may be large differences between one-time and repeating fertilizations. With repetition, sufficient macronutrients may get transported away from the upper ocean such that continued iron fertilization produces diminishing effects. These issues can be explored with this set of simulations.

\section{Perform, analyze, and publish a range of simulations of various "what-if" scenarios}

The following simulations would probably be done after most of the prior simulations, with the exception of the remineralization length scale simulations, because it is important to resolve the importance or unimportance of this factor as soon as possible. Many of these simulations would require the development of new equilibrium states of the model, involving thousands of years of simulated ocean circulation. Therefore, we will choose carefully among the following.

What if remineralization length scales could be controlled?

We will perform simulations in which the increase in carbon export is remineralized with different length scales

What if "Redfield" ratios of exported carbon could be controlled?

How would it affect long-term sequestration efficiency nutrients (e.g., P, N, Fe) were to remineralize more rapidly than carbon?

What if we could fertilize in such a way that only some functional groups would receive the benefit of the added Fe (e.g., only diatoms or only coccolithophorids).

\section{Detail of proposed experiments}

\section{1-D and 3-D models}

The 1-D model is an efficient and useful workbench to explore many of the questions listed in Part 1 (above). Where possible and appropriate we will perform simulations first in a 1-D test bed to see if the full 3-D simulation is likely to produce an important result. [For example, if the 1-D model results suggest that varying remineralization length scales has little effect on sequestration efficiency, then this need not be pursued in 3-D; if the 1-D model suggests it is important, then the effect will be explored in greater detail in the 3-D model.

The one-dimensional simulations described above will help to delineate which processes are likely to be important for predicting the effectiveness and consequences of ocean fertilization. The 3-D ocean GCM simulations are much more time consuming, so these runs must be chosen more carefully, especially if they require a new model "spin-up" (i.e., a new statisticallystationary steady state), as this requires thousands of simulated model years.

However, some issues can only be explored if the spatial component is adequately represented.

Here, we list a set of problems and solution approaches that is larger than we will actually be able to accomplish. Due to the nature of scientific work, some problems will prove to be 
important and easy, some important and hard. (We will avoid unimportant hard problems.) One contribution we will make is helping to determine where each problem falls on the important to unimportant spectrum, and to help determine what kind of effort [beyond the work proposed here] would be necessary to conclusively answer these questions.

\section{Addressing important questions}

We note that the questions below can easily be transformed into hypotheses by turning the question into statement.

\section{Effectiveness at storing carbon}

How much, locally, will biogenic carbon export (and macronutrient export) increase for various fertilization strategies?

We can get some idea of the effectiveness of various ocean fertilization strategies by performing simulated fertilizations in the 1-D transport model. For example, we can compare continuous fertilization with fertilization at different times of the year? For example, is it better to contribute to a pre-existing bloom, or fertilize in a non-bloom period? Once we have established some range of different behavior in the 1-D test bed, we can perform several ocean GCM simulations using these fertilization strategies to see how the system behaves when lateral fluxes are considered.

A pulse of iron fertilization may increase export for a short amount of time, but does it increase total annual export?

Iron fertilization may increase export in the bloom period immediately after fertilization, but as the macronutrients are consumed export may be diminished during the post-bloom period. The 1D model can be used to explore to what extent the post-bloom reduction in export might offset the increased export that occurs during the bloom period.

Iron fertilization may increase export locally, but does it increase global export?

Ocean iron fertilization is attempting to increase the fraction of macronutrients leaving the mixed layer that is associated with organic carbon export. It is possible that fertilization could speed the utilization of this macronutrient without increasing overall carbon export. This could occur, for example, in a situation in which nutrient-rich water upwells, and spreads into surface waters of a gyre. By the time the upwelled water subducts again nearly all of the macronutrients may be depleted; in some localities, fertilizing may simply speed up nutrient utilization without increasing total utilization. We can use the 3-D model to assess effectiveness as a function of location and mode of fertilization.

Which fertilization strategies would maximize ocean $\mathrm{CO} 2$ uptake per unit iron added?

Export is only one factor in the equation. For ocean fertilization to be an effective sequestration strategy, some of the export must be compensated for by a flux of carbon from the atmosphere to the ocean. Are the strategies that produce the most export necessarily the strategies that produce the greatest air-to-sea $\mathrm{CO} 2$ flux? The set of 3-D simulations under various fertilization scenarios. 
Do different fertilization strategies preferentially select for coccolithophorids, diatoms, Trichodesmium, etc., and what effect does this selection have on carbon storage?

In the 1-D model, coefficients can be modified to favor one functional group of organisms over another. To what extent does this affect air-sea $\mathrm{CO}_{2}$ fluxes for a fixed rate of nutrient supply? Do the different fertilization scenarios tend to favor different functional groups?

How does macronutrient transport affect the long-term application of fertilization as a sequestration strategy?

Increased export of organic matter tends to deplete macronutrient concentrations in the upper ocean, which would tend to diminish biological productivity, making continued fertilization less effective. This effect has been observed in ocean GCM simulations. How does this effect vary with the length-scales for macronutrient remineralization? These issues can be explored in the 1D model.

Will there be changes in calcareous plankton production and export that could affect air-sea carbon fluxes?

The production of $\mathrm{CaCO} 3$ in the upper ocean, and its export to the ocean interior, tends to drive a $\mathrm{CO} 2$ flux from the ocean to the atmosphere. Thus, if coccolithophorids or other calcareous plankton are stimulated, at least part of the benefits of organic carbon export will be compensated for by inorganic carbon export. The 1-D model can be used to test how important this effect is in determining the effectiveness of various ocean fertilization proposals?

Where does exported carbon, and nutrients, remineralize in the water column?

Jorge Sarmiento presented a stimulating result at the 2002 Ocean Sciences Meeting. He found that even if increased carbon export were transported to the sea floor, where it may be expected to reside for hundreds of years, the effect on air-sea $\mathrm{CO} 2$ fluxes might diminish in years or decades. He speculated that there is some effective short-term return of some of this carbon, because the increased carbon export generates an increased mixed-layer to upper thermocline carbon gradient, resulting in an increased flux of carbon from the upper thermocline to the mixed-layer. This conjecture, suggesting a relative insensitivity to remineralization depth, can be explored with a 1-D model. The results of this exploration are very important, as it directly relates to the extent to which it is important to characterize remineralization length scales for carbon.

Is remineralization "Redfield"?

If nutrients are selectively scavenged from sinking detrital matter, this would allow exported nutrients to recycle through the euphotic zone more rapidly than would exported carbon. Effectively, this would allow added nutrients to effectively export carbon several times per nutrient addition. We will use the 1-D model to explore how much amplification of sequestration effectiveness there is as a function of nutrient and carbon remineralization length scales?

Can added iron recycle and thereby repeatedly fertilize the surface ocean?

After iron is added to the surface ocean and exported with biogenic matter, will that iron ever return to the surface ocean to support additional new production? The 1-D model can be used to see how much recycling there is in the base model configuration, and how this recycling is affected by changes in the representation of iron chemistry and ligand binding. 
Which fertilization strategies would maximize ocean $\mathrm{CO} 2$ uptake per unit iron added?

The 3-D model can be used to help identify the optimal spatial scale, location, and fertilization protocol, to sequester carbon in the ocean. Effectiveness will be measured as the change in ocean storage as a function of time resulting from an addition of iron. Some locations may export carbon effectively, only for it to be quickly returned to the upper ocean; other regions may not be so susceptible to artificially enhanced export, but may retain

Do different fertilization strategies preferentially select for coccolithophorids, diatoms, Trichodesmium, etc., and what effect does this selection have on carbon storage?

Different classes of phytoplankton have different properties affecting ocean $\mathrm{CO} 2$ storage, such as inorganic carbon production and nitrogen fixation. Is it possible to characterize the ocean in terms of where each class is most easily stimulated and what its effect is on carbon storage.

How does macronutrient transport affect the long-term application of fertilization as a sequestration strategy?

If large tracts of the ocean were fertilized for many years, the increased export of organic matter would tend to deplete macronutrient concentrations in the upper ocean. This reduction in macronutrient content would tend to diminish biological productivity, making continued fertilization less effective. It is unknown how important this dynamic is, as a function of scale and duration of fertilization.

Will there be changes in calcareous plankton production and export that could affect air-sea carbon fluxes?

The export of the tests of calcareous plankton transports alkalinity from the surface ocean to the ocean interior or sediments. This diminishes the alkalinity of the surface ocean, which tends to drive a $\mathrm{CO} 2$ flux into the atmosphere. Iron fertilization will affect the production and export of $\mathrm{CaCO} 3$. It is important to understand the role of this production in affecting ocean carbon storage.

Where does exported carbon, and nutrients, remineralize in the water column?

Many questions about the effectiveness of ocean carbon sequestration depend on the depth to which the exported carbon (and associated nutrients) is transported. For example, carbon transported to the $3 \mathrm{~km}$ depth in the North Pacific may remain in the ocean for a thousand years, whereas carbon in the upper thermocline might be ventilated to the atmosphere with a few years. [It has been pointed out that even if the carbon is exported to the ocean bottom, there is some effective short-term return of some of this carbon, because the increased carbon export generates an increased mixed-layer to upper thermocline carbon gradient, resulting in an increased flux of carbon from the upper thermocline to the mixed-layer.]

Is remineralization "Redfield"?

Furthermore, the ideal situation for sequestration effectiveness would be would be one in which organic carbon is transported more deeply than nutrients. This would allow the nutrients to cycle back up to the surface more rapidly than the organic carbon, diminishing the loss of effectiveness associated with transporting macronutrients away from the euphotic zone.

Can added iron recycle and thereby repeatedly fertilize the surface ocean? 
If added iron were to support export production, remineralize, and then be transported back up to the surface ocean, then this added iron could act to repeatedly fertilize the ocean. Is this a plausible hypothesis? What would the magnitude of this effect be?

How much, locally, will biogenic carbon export (and macronutrient export) increase for various fertilization strategies?

Most global ocean GCM simulations have represented iron fertilization by computing the organic carbon export that would be needed to draw phosphate concentrations down to zero. More sophisticated calculations have been made using regional models, but these are unable to predict long-term effectiveness.

How best to represent the surface boundary condition for ocean fertilization simulations?

Two different types of atmospheric boundary are commonly applied to ocean sequestration simulations (Caldeira et al., 2001). In one set of boundary conditions, atmospheric $\mathrm{CO} 2$ content is specified. In the other set of boundary conditions, fluxes into and out of the ocean change both atmospheric and oceanic $\mathrm{CO} 2$ content, and the ocean responds to that new boundary condition. For direct injection, this change of boundary condition changes the predicted effectiveness from a case in which all of the injected $\mathrm{CO} 2$ leaks to the atmosphere on a time scale of 300 years to one in which $80 \%$ of the carbon remains permanently sequestered in the ocean. [Both of these statements are true, as long as we are clear what the word "carbon" is referring to in each of the statements.]

Sarmiento and coworkers found that significant leakage to the atmosphere occurred within a few years, even if the organic flux was remineralized on the ocean bottom. Was the leakage of $\mathrm{CO} 2$ observed by Sarmiento and coworkers a result of the boundary condition applied? Did the reduction in $\mathrm{CO} 2$ locally cause a broad outgassing over the remainder of the ocean?

\section{Unintended consequences}

Is there any danger of producing irreversible changes to ocean ecosystems?

In the 1-D model, we can explore the issue of whether (and, if so, how long it takes) for ecosystems to return to the pre-fertilized state following an application of Fe. This is important for several reasons. If it can be shown that extensive fertilization can produce a permanent change in ecosystem structure, this would have to be taken into consideration prior to performing any such fertilization. Of course, if the model returns to the status quo ante, this is no guarantee that the real system will have this property. However, if the model demonstrates reason for concern, this should stimulate additional research in this area.

If the transport of macronutrients away from the euphotic zone resulting from long-term fertilization leaves the upper ocean deprived of macronutrients, the time scale for ecosystem recovery may be governed by the time scale of recovery of the nutrient fields. This time scale is probably closely related to the duration of the fertilization. Again, these issues can be explored in the 1-D version of the model.

Would fertilization favor some biogeochemical groups over others?

Given the range of fertilization scenarios in the 1-D model, are there consistencies in which biogeochemical (or functional) groups seem to be favored. Are some groups consistently winners and others consistently losers? What impact would this have on ocean biogeochemistry? 
What is the impact of ocean fertilization on fisheries?

If fertilization is designed to maximize export, it is not necessarily true that more photosynthate would be provided to the upper trophic levels that constitute most of the world's fisheries. While fish are not explicitly represented in the model, meso-zooplankton are represented. We can use the amount of food supplied to the highest trophic level in the model to make some conjectures about the response of these trophic levels to the various fertilization scenarios.

\section{Unintended consequences}

What are the long-term $\mathrm{pH}$ consequences of extensive long-term ocean fertilization?

If the ocean were fertilized for an extended amount of time over a broad area, significant amounts of carbon may be transferred from the upper ocean to the ocean interior. This would tend to diminish $\mathrm{pH}$ impacts of $\mathrm{CO} 2$ release on organisms that dwell in the upper ocean [e.g., calcareous plankton, coral reefs] while exacerbating $\mathrm{pH}$ effects on organisms that live in the middepth waters. What is the magnitude of the $\mathrm{pH}$ impacts of widespread, long-term, ocean fertilization?

What will happen to the ocean oxygen concentrations?

Early studies have indicated that long-term widespread ocean fertilization could produce or expand anoxic regions in the ocean. Would the avoidance of new oxygen-depleted zones significantly impact the amount of carbon that could be sequestered by ocean fertilization? What are the oxygen consequences of intermittent or patchy fertilization?

Will other radiatively active gases be affected by iron fertilization?

Phytoplankton produce DMS, nitrous oxides, and other radiatively active gases. If ocean fertilization were to produce ocean ecosystems that produce more DMS in remote marine environments, this could make ocean sequestration more effective at combating global warming; on the other hand, nitrous oxides are powerful greenhouse gases, and if these ecosystems were to produce greater amounts of nitrous oxides, this could diminish the effectiveness of ocean fertilization. Initial calculations suggest that these are second order effects; nevertheless, they need to be carefully and quantitatively assessed.

Is there any danger of producing irreversible changes to ocean ecosystems?

If an area of the ocean is fertilized for a prolonged period of time and then the fertilization is halted, will the ecosystem return to the status quo ante, and, if so, how long will it take to return? This question is important to answer because if a fertilization project were to start, and then a problem was discovered, it would be important to know whether the system could return to its unperturbed state. Such would not be the case, for example, if ocean fertilization were to have the capacity to drive species to extinction. Initial results indicate that ocean ecosystems are fairly resilient and could recover on a time scale that is similar to the duration of the fertilization.

Would fertilization favor some biogeochemical groups over others?

Would fertilization tend to favor coccolithophorids or diatoms? Would nitrogen-fixing organisms become more widespread? What might the unintended consequences for ecosystem structure of various fertilization strategies? 
What is the impact of ocean fertilization on fisheries?

Would fertilization for carbon sequestration diminish fishery yields [because more nutrients and organic matter are being export to the ocean interior] or increase fishery yields [because of enhanced photosynthesis]? Are there trade-offs between fishery considerations and sequestration considerations, or are the goals of increasing fish yields and decreasing greenhouse gas concentrations well aligned?

\section{Schedule}

\section{Year 1}

The first year of the project, we will

- get a cleaned up version of PISCES out on the web

- install PISCES in our ocean GCM

- spin up the model to a stationary state ( 4000 yr of simulation)

- make a 1-D (depth) version of PISCES

- perform a set of sensitivity experiments addressing as many questions in part 1 as possible using the 1-D version of the PICES model.

- perform initial fertilization simulations

\section{Year 2}

The second year of the project, we will

- Add a diagnostic nitrogen cycle to the model. In this approach, we estimate nitrogen fixation rates by assuming exported organic matter is Redfield; any deficit in nitrate relative to phosphate is assumed to have been supplied by nitrogen fixation. This is balanced in steady state by denitrification in hypoxic regions of the oceans.

- Perform additional fertilization scenarios with the modified PISCES biogeochemical model, focusing on the factors that the 1-D model suggests are most important.

- Work on developing a nitrogen cycle (in collaboration with IPSL) for the PISCES model

\section{Year 3}

The third year of this project, we will

- perform a full set of experiments in the model with full cycles of N, Si, P, Alk, O2, CO2

\section{Summary}

\section{Research project objectives}

The primary objectives of this project are to assess, and improve our understanding of:

2. The effectiveness of various proposals to intentionally store carbon in the ocean through fertilization of the surface ocean with iron and/or macronutrients;

3. The $\mathrm{pH}$ and other biologically relevant consequences of long-term and extensive ocean fertilization;

4. First order ecological consequences of ocean fertilization.

In greater detail, we wish to examine: 
- Does patchy or intermittent fertilization result in increased local carbon export?

- To what extent is increased export [local in time and space] compensated for by decreased export either in the future or in neighboring regions?

- To what extent is increased export compensated for by an increased quasi-diffusive flux of carbon from the upper thermocline to the mixed layer?

- How do predictions made with a more realistic biological model compare with those made with simple biological models?

- What is the long-term effectiveness of ocean fertilization via different strategies [e.g., patchy versus widespread, intermittent versus prolonged] in different areas?

- What are the long-term pH consequences for the deep ocean of prolonged or widespread ocean fertilization?

- Will iron fertilization increase rates of nitrogen fixation?

- Will iron fertilization result in ecological shifts, say from diatom-dominated ecosystems to coccolithophorid-dominated ecosystems [say, as $\mathrm{Si}$ is depleted from fertilized regions]?

- How well does the coupled biology/physics model simulate observations from iron fertilization experiments, including SOFeX?

- What processes need to be included in the models, to better reproduce effects observed in iron fertilization experiments?

- What should the next experiment measure to better constrain the models?

\section{Methods of accomplishment}

Here, we propose to use what we believe to be the best global ocean biogeochemical model in the world (PISCES) and apply it to perform the most realistic simulations of various iron fertilization scenarios. PISCES is currently used by both the Max Planck Institute (MPI) in Hamburg, Germany, and the Institute Pierre Simon Laplace (IPSL) in Saclay, France, in their respective coupled ocean/atmosphere/carbon-cycle modeling efforts. The model represents diatoms, coccolithophorids, nitrogen fixers, and two classes of zooplankton. This model considers $\mathrm{Fe}, \mathrm{N}, \mathrm{P}, \mathrm{O} 2, \mathrm{Si}$, alkalinity, and carbon; for some of these it considers dissolved inorganic and organic, as well as particulate, forms.

Heretofore, most ocean sequestration simulations have either been performed on a global scale, but with an extremely rudimentary representation of marine biota (e.g., Sarmiento and Orr, 1991), or with a reasonably good biotic model, but over a limited domain (e.g., Barber, Chai, et al., Ocean Sciences, 2002). Installing PISCES in an ocean GCM here, would allow us to perform the most realistic global scale simulations of iron fertilization, with a minimum of model development effort. Instead of simply reducing surface phosphate to zero, as has been done first by Sarmiento and his coworkers (and later by this PI and others), or simply assuming an increase in primary productivity resulting from iron fertilization, as has been done by Barber and his coworkers. We, for the first time, could add simulated iron to our simulated ecosystem and presumable predict a more realistic response [e.g., phosphate will not be reduced to zero concentration] that can be directly compared with iron fertilization experiments such as SOFeX.

Our general approach would be to install the PISCES model with a minimum of modification, and perform an initial suite of simulations of both iron fertilization experiments (e.g., SOFeX) 
and proposed iron fertilization strategies. Based on the simulated experiments, we will analyze model deficiencies with respect to the observations and use this analysis to improve future versions of the model. PISCES was derived from a model originated by Ernst Maier-Reimer and Katerina Six at MPI, but was greatly extended by Olivier Aumont working both at IPSL and MPI. Olivier Aumont was a student of Jim Orr. Jim Orr performed the first iron fertilization simulations, and he is now spending his sabbatical year with me. As a result of this relationship, I have obtained a copy of the PISCES model with permission to install it in the LLNL ocean GCM. As a result of this project, DOE will have a tested integrated modeling framework that can make predictions of large-scale consequences of both iron fertilization and direct injection. This source code for and results from this set of models will be freely distributed.

This project is markedly different from all currently funded projects. Current funding applies to direct injection and geochemical modeling only; this proposal applies to iron fertilization and ecosystem modeling. Nevertheless, there is some synergy to be gained by having iron fertilization experiments performed in the same model and by the same people who are performing direct injection simulations. For example, we can use already-developed $\mathrm{pH}$ diagnostics to look at iron fertilization results. Our simulations can help provide context and guidance for biological observations within the ocean carbon sequestration research program.

\section{Conclusion}

A project with a clear strategy to achieve the most-realistic ocean fertilization simulations yet performed in a global model, with an assessment of and improvement in the reliability of those predictions using results from iron fertilization experiments such as SOFeX.

\section{Subcontract and consortium arrangements Literature cited}

Boyd, PW; Watson, AJ; Law, CS; Abraham, ER; and others. A mesoscale phytoplankton bloom in the polar Southern Ocean stimulated by iron fertilization.

NATURE, 2000 OCT 12, V407 N6805:695-702.

FUHRMAN JA; CAPONE DG.

POSSIBLE BIOGEOCHEMICAL CONSEQUENCES OF OCEAN FERTILIZATION.

LIMNOLOGY AND OCEANOGRAPHY, 1991 DEC, V36 N8:1951-1959.

Trull, T; Rintoul, SR; Hadfield, M; Abraham, ER.

Circulation and seasonal evolution of polar waters south of Australia:

Implications for iron fertilization of the Southern Ocean.

DEEP-SEA RESEARCH PART II-TOPICAL STUDIES IN OCEANOGRAPHY, 2001, V48

N1 1-12:2439-2466.

Pub type: Review.

Landry, MR; Ondrusek, ME; Tanner, SJ; Brown, SL; and others.

Biological response to iron fertilization in the eastern equatorial Pacific

(IronEx II). I. Microplankton community abundances and biomass. 
Bollens, GCR; Landry, MR.

Biological response to iron fertilization in the eastern equatorial Pacific

(IronEx II). II. Mesozooplankton abundance, biomass, depth distribution and grazing.

MARINE ECOLOGY-PROGRESS SERIES, 2000, V201:43-56.

Walsh, JJ; Dieterle, DA; Lenes, J.

A numerical analysis of carbon dynamics of the Southern Ocean phytoplankton

community: the roles of light and grazing in effecting both sequestration of

atmospheric $\mathrm{CO} 2$ and food availability to larval krill.

DEEP-SEA RESEARCH PART I-OCEANOGRAPHIC RESEARCH PAPERS, 2001 JAN, V48

N1:1-48.

Pub type: Review.

Rau, GH; Caldeira, K.

Minimizing effects of $\mathrm{CO} 2$ storage in oceans.

SCIENCE, 2002 JAN 11, V295 N5553:275-276.

Pub type: Letter.

Caldeira, K; Duffy, PB.

The role of the Southern Ocean in uptake and storage of anthropogenic carbon dioxide.

SCIENCE, 2000 JAN 28, V287 N5453:620-622.

Falkowski, PG.

Evolution of the nitrogen cycle and its influence on the biological sequestration of $\mathrm{CO} 2$ in the ocean.

NATURE, 1997 MAY 15, V387 N6630:272-275.

WATSON AJ; LAW CS; VANSCOY KA; MILLERO FJ; and others. MINIMAL EFFECT OF IRON FERTILIZATION ON SEA-SURFACE CARBON DIOXIDE CONCENTRATIONS.

NATURE, 1994 SEP 8, V371 N6493:143-145.

Antia, AN; Koeve, W; Fischer, G; Blanz, T; and others.

Basin-wide particulate carbon flux in the Atlantic Ocean: Regional export

patterns and potential for atmospheric $\mathrm{CO} 2$ sequestration.

GLOBAL BIOGEOCHEMICAL CYCLES, 2001 DEC, V15 N4:845-862.

JOOS F; SARMIENTO JL; SIEGENTHALER U.

ESTIMATES OF THE EFFECT OF SOUTHERN OCEAN IRON FERTILIZATION ON

ATMOSPHERIC CO2 CONCENTRATIONS.

NATURE, 1991 FEB 28, V349 N6312:772-775.

PENG TH; BROECKER WS.

DYNAMICAL LIMITATIONS ON THE ANTARCTIC IRON FERTILIZATION STRATEGY. NATURE, 1991 JAN 17, V349 N6306:227-229. 
PENG TH; BROECKER WS.

FACTORS LIMITING THE REDUCTION OF ATMOSPHERIC CO2 BY IRON FERTILIZATION.

LIMNOLOGY AND OCEANOGRAPHY, 1991 DEC, V36 N8:1919-1927.

Landry, MR; Constantinou, J; Latasa, M; Brown, SL; and others.

Biological response to iron fertilization in the eastern equatorial Pacific

(IronEx II). III. Dynamics of phytoplankton growth and microzooplankton grazing.

MARINE ECOLOGY-PROGRESS SERIES, 2000, V201:57-72.

Cavender-Bares, KK; Mann, EL; Chisholm, SW; Ondrusek, ME; and others.

Differential response of equatorial Pacific phytoplankton to iron

fertilization.

LIMNOLOGY AND OCEANOGRAPHY, 1999 MAR, V44 N2:237-246.

Lenes, JM; Darrow, BP; Cattrall, C; Heil, CA; and others.

Iron fertilization and the Trichodesmium response on the West Florida

shelf.

LIMNOLOGY AND OCEANOGRAPHY, 2001 SEP, V46 N6:1261-1277.

1

16. JOOS F; SARMIENTO JL; SIEGENTHALER U.

ESTIMATES OF THE EFFECT OF SOUTHERN OCEAN IRON FERTILIZATION ON ATMOSPHERIC CO2 CONCENTRATIONS.

NATURE, 1991 FEB 28, V349 N6312:772-775.

KURZ KD; MAIERREIMER E.

IRON FERTILIZATION OF THE AUSTRAL OCEAN - THE HAMBURG MODEL ASSESSMENT. GLOBAL BIOGEOCHEMICAL CYCLES, 1993 MAR, V7 N1:229-244.

COALE KH; JOHNSON KS; FITZWATER SE; GORDON RM; and others. A MASSIVE PHYTOPLANKTON BLOOM INDUCED BY AN ECOSYSTEM-SCALE IRON FERTILIZATION EXPERIMENT IN THE EQUATORIAL PACIFIC OCEAN.

NATURE, 1996 OCT 10, V383 N6600:495-501.

COOPER DJ; WATSON AJ; NIGHTINGALE PD.

LARGE DECREASE IN OCEAN-SURFACE CO2 FUGACITY IN RESPONSE TO IN SITU IRON FERTILIZATION.

NATURE, 1996 OCT 10, V383 N6600:511-513.

Chisholm, SW; Falkowski, PG; Cullen, JJ.

Oceans - Dis-crediting ocean fertilization.

SCIENCE, 2001 OCT 12, V294 N5541:309-310.

Trull, T; Rintoul, SR; Hadfield, M; Abraham, ER.

Circulation and seasonal evolution of polar waters south of Australia:

Implications for iron fertilization of the Southern Ocean.

DEEP-SEA RESEARCH PART II-TOPICAL STUDIES IN OCEANOGRAPHY, 2001, V48

N11-12:2439-2466. 
Pub type: Review.

Gribbin, J. "Any old Iron?", NATURE 331: 570-570 1988

Caldeira, K., A.K. Jain and M.I. Hoffert. Energy implications of uncertainty in climate sensitivity to increased atmospheric $\mathrm{CO}_{2}$ content, Science, submitted.

Caldeira, K., M.E. Wickett, and P.B. Duffy. Depth, radiocarbon and the effectiveness of direct $\mathrm{CO}_{2}$ injection as an ocean carbon sequestration strategy. Geophysical Research Letters, submitted.

Herzog, H., K. Caldeira, and J. Reilly. An issue of permanence: Assessing the effectiveness of ocean carbon sequestration, Climatic Change, submitted.

Hoffert, M.I., K. Caldeira, G. Benford, D.R. Criswell, C. Green, H. Herzog, J.W. Katzenberger, H.S. Kheshgi, K.S. Lackner, J.S. Lewis, W. Manheimer, J.C. Mankins, G. Marland, M.E. Mauel, L.J. Perkins, M.E. Schlesinger, T. Volk, and T.M.L. Wigley, Advanced technology paths to global climate stability: Energy for a greenhouse planet, Science, submitted.

Randerson, J.T., I. Enting, E. Schuur, K. Caldeira, and I. Y. Fung' Seasonal and spatial dynamics of troposphere ${ }^{-14} \mathrm{CO}_{2}:$ Fossil fuel, ocean, stratosphere, and terrestrial biosphere components, Global Biogeochemical Cycles, submitted.

Wickett, M.E., K. Caldeira and P.B. Duffy, High-resolution simulations of oceanic direct-injection of anthropogenic $\mathrm{CO}_{2}$ and $\mathrm{CFC}$ uptake, Journal of Geophysical Research (Oceans), submitted.

Duffy, P.B., M.E. Wickett, and K. Caldeira, Effect of horizontal grid resolution on the near-equilibrium solution of a global ocean/sea-ice model, Journal of Geophysical Research (Oceans), in press.

Lutz, M., R.L. Dunbar, and K. Caldeira, Regional variability in the vertical flux of particulate organic carbon in the ocean interior, Global Biogeogeochemical Cycles, in press.

Dutay, J.-C., J.L. Bullister, S.C. Doney, J.C. Orr, R. Najjar, K. Caldeira, J.-M. Champin, H. Drange, M. Follows, Y. Gao, N. Gruber, M.W. Hecht, A. Ishida, F. Joos, K. Lindsay, G. Madec, E. Maier-Reimer, J.C. Marshall, R.J. Matear, P. Monfray, G.-K. Plattner, J. Sarmiento, R. Schlitzer, R. Slater, I.J. Totterdell, M.-F. Weirig, Y. Yamanaka, and A. Yool, Evaluation of ocean model ventilation with CFC11: comparison of 13 global ocean models. Ocean Modelling 4, 89-120, 2002.

Rau, G.H., and K. Caldeira, Minimizing effects of $\mathrm{CO}_{2}$ storage in oceans (letter). Science 276, 275-276, 2002.

Caldeira, K., and P.B. Duffy, The role of the Southern Ocean in uptake and storage of anthropogenic carbon dioxide, Science 287, 620-622, 2000.

Caldeira, K., M.I. Hoffert, and A. Jain, Simple ocean carbon cycle models, in The Carbon Cycle, T.M.L. Wigley and D.S. Schimel, eds., Cambridge University Press, Cambridge, United Kingdom, 199_211, 2000.

Caldeira, K., and G.H. Rau, Accelerating carbonate dissolution to sequester carbon dioxide in the ocean: Geochemical implications, Geophysical Research Letters, 27, 225-228, 2000.

Guilderson, T.P., K. Caldeira, and P.B. Duffy, Radiocarbon as a diagnostic tracer in ocean and carbon cycle modeling, Global Biogeochemical Cycles, 14, 887-902, 2000.

Caldeira, K., and Berner, R., Seawater $\mathrm{pH}$ and atmospheric carbon dioxide (Technical comment), Science 286, 2043a-2043a, 1999.

Duffy, P.B., and Caldeira, K.G. Sensitivity of simulated salinities in a three dimensional ocean general circulation model to vertical mixing of destabilizing surface fluxes, Climate Dynamics 15, 81-88, 1999.

Rau, G.H., and Caldeira, K. Enhanced carbonate dissolution: A means of sequestering waste $\mathrm{CO}_{2}$ as ocean bicarbonate. Energy Conversion and Management 40, 1803-1813, 1999.

Caldeira, K., and R.A. Berner, The need for mass balance and feedback in the geochemical carbon cycle: Reply, Geology 26, 478-478, 1998.

Caldeira, K., and P.B. Duffy, Sensitivity of simulated CFC-11 distributions in a global ocean model to the treatment of salt rejected during sea-ice formation, Geophysical Research Letters 25, 1003-1006, 1998. 
Caldeira, K., G.H. Rau, and P.B. Duffy, Predicted net efflux of radiocarbon from the ocean and increase in atmospheric radiocarbon content, Geophysical Research Letters 25, 3811-3814, 1998.

Hoffert M.I., K. Caldeira, A.K. Jain, E.F. Haites, L.D.D. Harvey, S. D. Potter, M.E. Schlesinger, S. H. Schneider, R.G. Watts, T. M. L Wigley, and D. J. Wuebbles. Energy implications of future stabilization of atmospheric $\mathrm{CO}_{2}$ content. Nature 395, 881-884, 1998.

Stephens, B.B., Keeling, R.F., Sarmiento, J., Six, K., Murnane, R., and K. Caldeira, Atmospheric oxygen as a test of ocean carbon cycle models, Global Biogeochemical Cycles 12, 213-230, 1998.

Berner, R.A., and K. Caldeira, The need for mass balance and feedback in the geochemical carbon cycle, Geology 25, 955-956, 1997.

Duffy, P. B., and K. Caldeira, Sensitivity of simulated salinity in a three-dimensional ocean model to upper-ocean transport of salt from sea-ice formation, Geophysical Research Letters 24, 1323-1326, 1997.

Duffy, P.B., K. Caldeira, J. Selvaggi, and M.I. Hoffert, Effect of subgrid scale mixing parameterizations on simulated distributions of natural ${ }^{14} \mathrm{C}$, temperature, and salinity in a three-dimensional ocean general circulation model, Journal of Physical Oceanography 27, 498-523, 1997.

Wehner, M.F., P.G. Eltgroth, A.A. Mirin, P.B. Duffy, K.G. Caldeira, J.H. Bolstad, H. Wang, C.M. Matarazzo and U. Creach, Comprehensive climate system modeling on massively parallel computers, Mission Earth: Modeling and Simulation for a Sustainable Global System, 37-42, M.G. Clymer and C.R. Mechoso, eds., Society for Computer Simulation International, San Diego, California, 1997.

Caldeira, K., IPCC report, chapter and verse (corr.), Nature 383, 214-214, 1996.

Duffy, P.B., and K. Caldeira, $A$ three-dimensional model calculation of ocean uptake of bomb ${ }^{14} \mathrm{C}$ and implications for the global budget of bomb ${ }^{14} \mathrm{C}$, Global Biogeochemical Cycles 9, 373-375, 1995.

Duffy, P.B., P. Eltgroth, A. J. Bourgeois, and K. Caldeira, Effect of improved subgrid scale transport of tracers on uptake of bomb radiocarbon in the GFDL ocean general circulation model, Geophysical Research Letters 22, 1065-1068, 1995.

Caldeira, K. and M.R. Rampino, Aftermath of the end-Cretaceous mass extinction possible biogeochemical stabilization of the carbon cycle and climate, Paleoceanography 8, 515-525, 1993.

Caldeira, K., Enhanced Cenozoic chemical weathering and the subduction of pelagic carbonate, Nature 357, 578-581, 1992.

Caldeira, K., Evolutionary pressures on planktonic dimethylsulfide production, in, Schneider, S.H. and Boston, P., eds., Scientists on Gaia, MIT Press, Cambridge, MA, 153-158, 1991.

Caldeira, K., Evolutionary pressures on planktonic production of atmospheric sulphur, Nature 337, 632634, 1989. 


\section{Budget and budget explanation Other support for investigators}

Biographical sketches (max 2 pages per investigator)

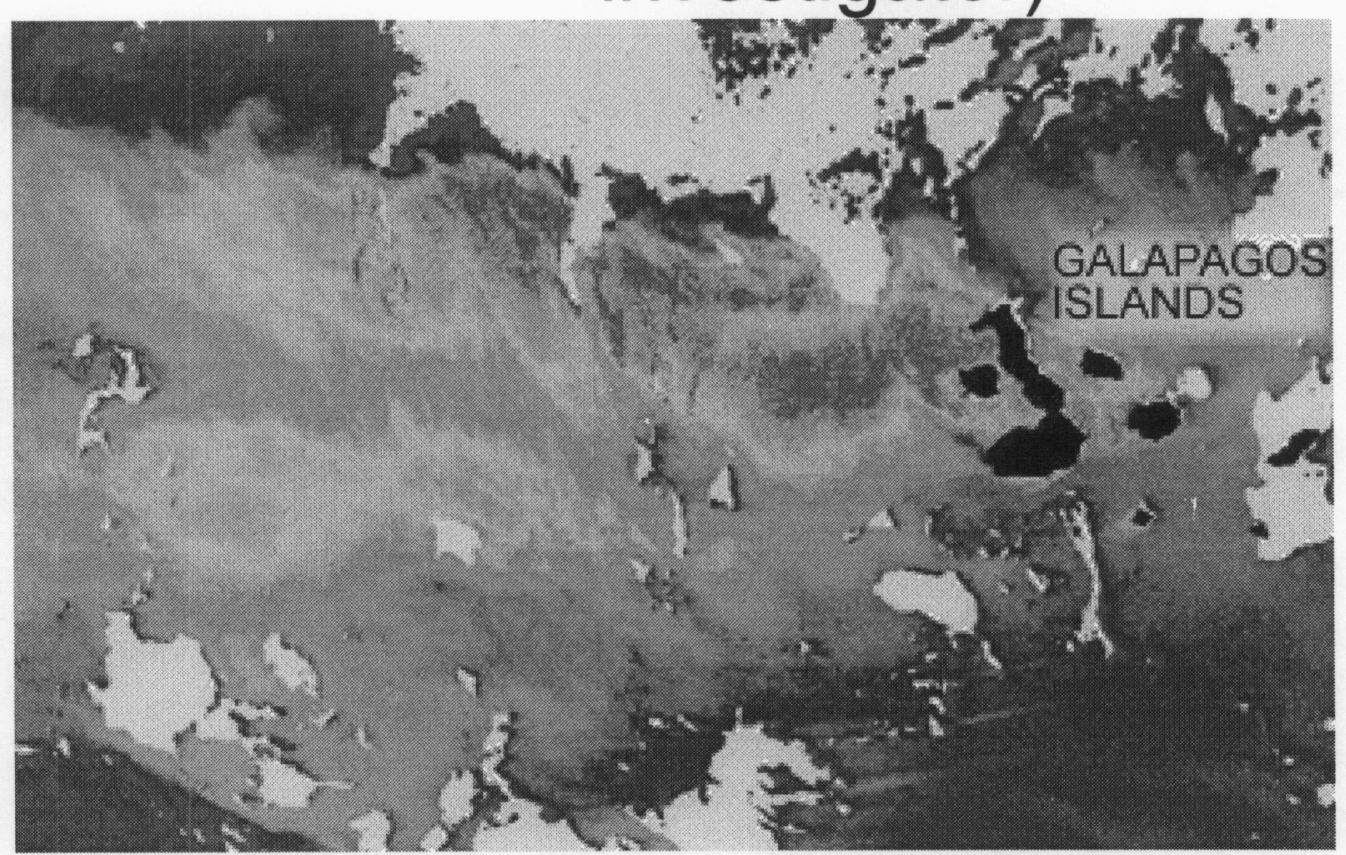

CZCS mostly diatoms 